\title{
Characterization of a Darkly Pigmented Mycelial Isolate of Sclerotinia sclerotiorum on Valencia Peanut in New Mexico
}

\author{
S. Sanogo, Plant Pathologist, Department of Entomology, Plant Pathology, and Weed Science, New Mexico State \\ University, Las Cruces, NM 88003; and N. Puppala, Peanut Breeder, Clovis Agricultural Science Center, New Mex- \\ ico State University, Clovis, NM 88101
}

\begin{abstract}
Sanogo, S., and Puppala, N. 2007. Characterization of a darkly pigmented mycelial isolate of Sclerotinia sclerotiorum on Valencia peanut in New Mexico. Plant Dis. 91:1077-1082.

A sclerotia-forming fungus was isolated from a peanut field in eastern New Mexico, where Valencia peanut is grown. The isolated fungus was typified by its darkly pigmented mycelium when grown on culture media, with pigmentation influenced by media. The optimal temperature range for mycelial growth was 20 to $25^{\circ} \mathrm{C}$. In pathogenicity tests, the fungus caused watersoaked and light tan lesions on stems at points of inoculation, and lesions progressed up the stems into petioles followed by collapse of leaves. White fluffy mycelium and sclerotia were present on inoculated plants. Based on the examination of morphological and cultural characteristics of sclerotia, apothecia, asci, and ascospores, the isolated fungus with darkly pigmented mycelium on culture media was identified as Sclerotinia sclerotiorum. This study is the first report of S. sclerotiorum on peanut in New Mexico.
\end{abstract}

Additional keywords: Arachis hypogaea, dark mycelial Sclerotinia, groundnut, Sclerotinia blight

Peanut, Arachis hypogaea L., is an economically important crop in the United States with a value of approximately $\$ 846$ million in 2005 (2). In eastern New Mexico, Valencia peanut, A. hypogaea subsp. fastigiata var. fastigiata, is a short-season crop, and production was valued at approximately $\$ 16$ million in 2005 (2). From August to December 2005, marketing price for peanut in New Mexico was 0.555 dollars/kg compared to other states for which prices ranged from 0.375 to 0.437 dollars $/ \mathrm{kg}$ (2). The major market for Valencia peanut is in the shell for human consumption. Most of the Valencia peanut produced in eastern New Mexico and western Texas is for consumption in the United States. Valencia peanut production was 31,350 tons on approximately 7,695 ha producing an average yield of $3,700 \mathrm{~kg} / \mathrm{ha}$. Valencia peanut is generally grown under sprinkler irrigation system. Peanut is planted in midMay and is harvested starting in the last week of September to mid-October depending on the weather during the growing season. Valencia peanut requires 500 to

Corresponding author: S. Sanogo

E-mail: ssanogo@nmsu.edu

Accepted for publication 2 April 2007.

doi:10.1094/PDIS-91-9-1077

(C) 2007 The American Phytopathological Society
$635 \mathrm{~mm}$ of water per cropping season, and matures in 130 to 135 days.

Peanut cultivation in the United States is constrained by numerous foliar and root diseases (14). Soilborne pathogens are the major constraint to peanut production in New Mexico. In 2005, while surveying peanut fields for soilborne fungal diseases in eastern New Mexico, plants with light tan to brown blighted stems (Fig. 1), branches, and leaves were discovered. On symptomatic stems, within the stem pith, and shredded stem tissue, white fluffy mycelium and large sclerotia $(>2 \mathrm{~mm})$ developed (Fig. 1). Less than $3 \%$ of the field was affected, and within these areas, disease incidence ranged from 5 to $10 \%$. Based on field diagnosis and the literature on peanut diseases (14), it was theorized that the sampled peanut plants were affected by Sclerotinia blight, caused by Sclerotinia minor or $S$. sclerotiorum $(3,20,21)$.

Sclerotinia blight has been reported in North Carolina and Virginia (20), Georgia (26), Nebraska (18), Oklahoma (24), and Texas (25). In New Mexico, a survey was conducted in 1991 for Sclerotinia blight in peanut fields, but the disease was not found (16). Yield loss from Sclerotinia blight may exceed $50 \%$ in fields with high incidence and severity of the disease (21). $S$. minor and S. sclerotiorum have a wide host range that includes crop and weed species (9). On peanut, $S$. minor is the most predominant pathogen causing Sclerotinia blight (21), and S. sclerotiorum is reported to be less virulent than $S$. minor (18). Characteristics of sclerotia and ascospores are two of the features used in distinguishing both species (13). Sclerotia of $S$. minor are smaller than those of $S$. sclerotiorum. In $S$. minor, the length of sclerotia ranges from 0.5 to $2 \mathrm{~mm}$ (13), whereas in $S$. sclerotiorum the length of sclerotia ranges from 1 to over $30 \mathrm{~mm}$ (4). Weight of sclerotia ranged from 0.05 to $0.08 \mathrm{~g}$ for $S$. sclerotiorum and from 0.0065 to $0.0125 \mathrm{~g}$ for $S$. minor based on 10 sclerotia (18). Ascospores are reported as tetranucleate in $S$. minor and binucleate in S. sclerotiorum (13).

This study reports on the characterization, identification, and pathogenicity of the sclerotia-producing fungus isolated from infected peanut plants.

\section{MATERIALS AND METHODS}

Fungal isolation. Three plants with blighted stems and branches, and displaying sclerotia and mycelium, were arbitrarily sampled from the affected field. The plants were placed in a plastic bag over ice in a cooler and transported to the laboratory for processing. Four sclerotia were collected from each of the three plants, wrapped in a piece of sterile cheesecloth (5 $\times 5 \mathrm{~cm}$ ), and submerged in $1 \%$ sodium hypochlorite solution for $1 \mathrm{~min}$. Sclerotia were then removed from the cheesecloth and rinsed in sterile distilled water, and blotted dry between two layers of sterile paper towel. Each of the selected sclerotia was individually plated on acidified potato dextrose agar (APDA; $39 \mathrm{~g} /$ liter of Difco PDA amended with $1 \mathrm{ml}$ of $85 \%$ lactic acid after autoclaving and prior to dispensing into petri plates) in a 9-cm-diameter plastic petri plate. Two fragments of mycelium visible on infected stems and branches were removed from each of the three plants with forceps, placed directly on APDA, and slightly pressed into the medium. Two segments of approximately 2 $\mathrm{cm}$ were cut off symptomatic stems and branches from each of the three plants and surface-disinfested as described above for sclerotia, except that the segments were submerged in $1 \%$ sodium hypochlorite 
solution for $2 \mathrm{~min}$. The 2-cm segments were sectioned into $1-\mathrm{cm}$ pieces, which were plated individually onto APDA. All petri plates with sclerotia, mycelium fragments, and stem tissues were maintained at 23 to $25^{\circ} \mathrm{C}$. Plates were monitored daily and emerging mycelial colonies were transferred to PDA. For further characterization and identification, a culture from a sclerotium, hereafter named isolate SS05$\mathrm{SC}$, was used. This isolate was maintained on PDA at $5^{\circ} \mathrm{C}$, and was used for sclerotial and apothecial production, temperature effects, pigmentation studies, pathogenicity tests, and screening of peanut cultivars.

Production of apothecia from sclerotia. To produce sclerotia, isolate SS05$\mathrm{SC}$ was transferred to PDA in 9-cmdiameter petri plates and incubated at $20^{\circ} \mathrm{C}$ in the dark for 3 weeks. Sclerotia were harvested with sterile forceps and used in the induction of apothecia. To induce apothecia production, modified procedures described by Huang et al. (11) and Tu (23) were used. Sclerotia were stored on saturated sterile sand in deep petri dishes at $5^{\circ} \mathrm{C}$ for 6 weeks before being moved to a $20^{\circ} \mathrm{C}$ incubator under continuous fluorescent irradiation at $260 \mu \mathrm{mol} / \mathrm{m}^{2} / \mathrm{s}$.

Characterization of apothecia, asci, and ascospores. Apothecia were harvested from sclerotia and prepared for light microscopy. Each apothecium without the stipe was gently squashed between two glass slides and mounted in sterile distilled water or acid fuchsin. Squash mounts of apothecia were examined under a Zeiss Axioplan compound light microscope (Carl Zeiss, Inc., Thornwood, NY) equipped with a MicroMax Cooled CCD Camera, and image acquisition was done with a WinView32 software program (Princeton Instruments, Inc., Trenton, NJ).

Effect of temperature on growth. Mycelium plugs, $1 \mathrm{~cm}$ diameter, were cut from a 14-day culture of S. sclerotiorum maintained on PDA at $5^{\circ} \mathrm{C}$ in the dark. The plugs were placed on PDA in 9-cmdiameter petri plates and incubated at 5 , $10,15,20,25,30$, and $35^{\circ} \mathrm{C}$ in the dark. The radius of colonies was measured at 24 and $48 \mathrm{~h}$ after incubation. Six plates were used per temperature, and the experiment was repeated.

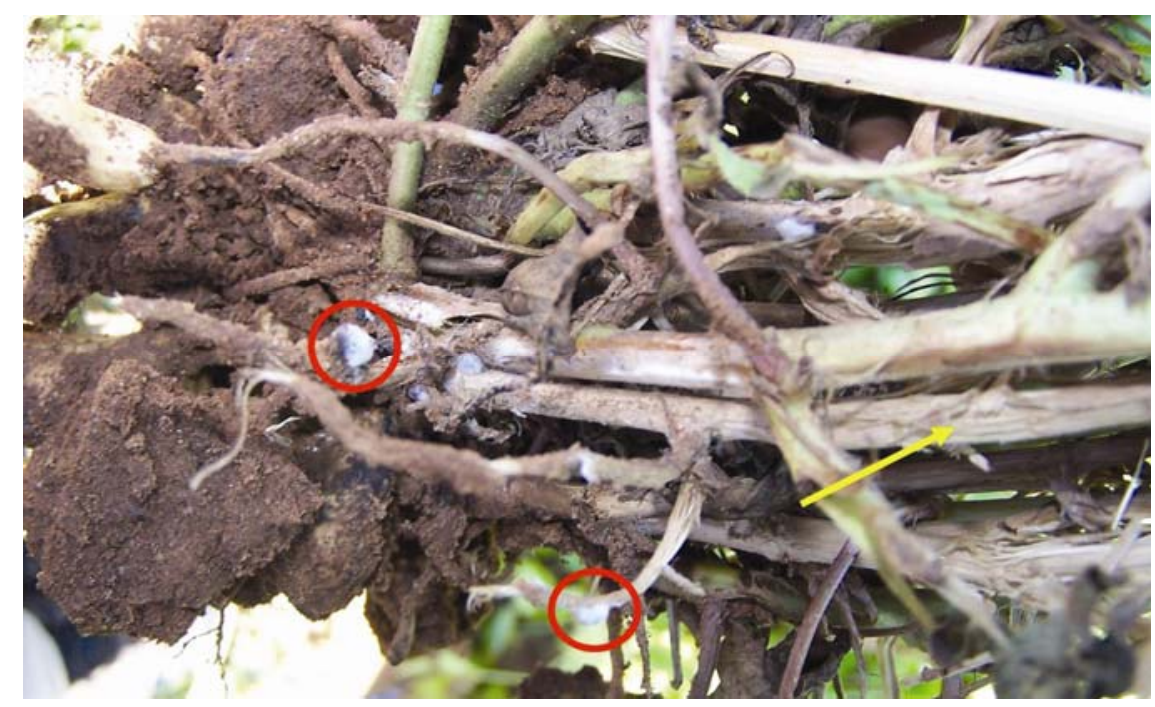

Fig. 1. Field-infected peanut plants displaying white mycelium growth and sclerotia (shown within red circles) of Sclerotinia sclerotiorum, and shredded stem tissue (yellow arrows).
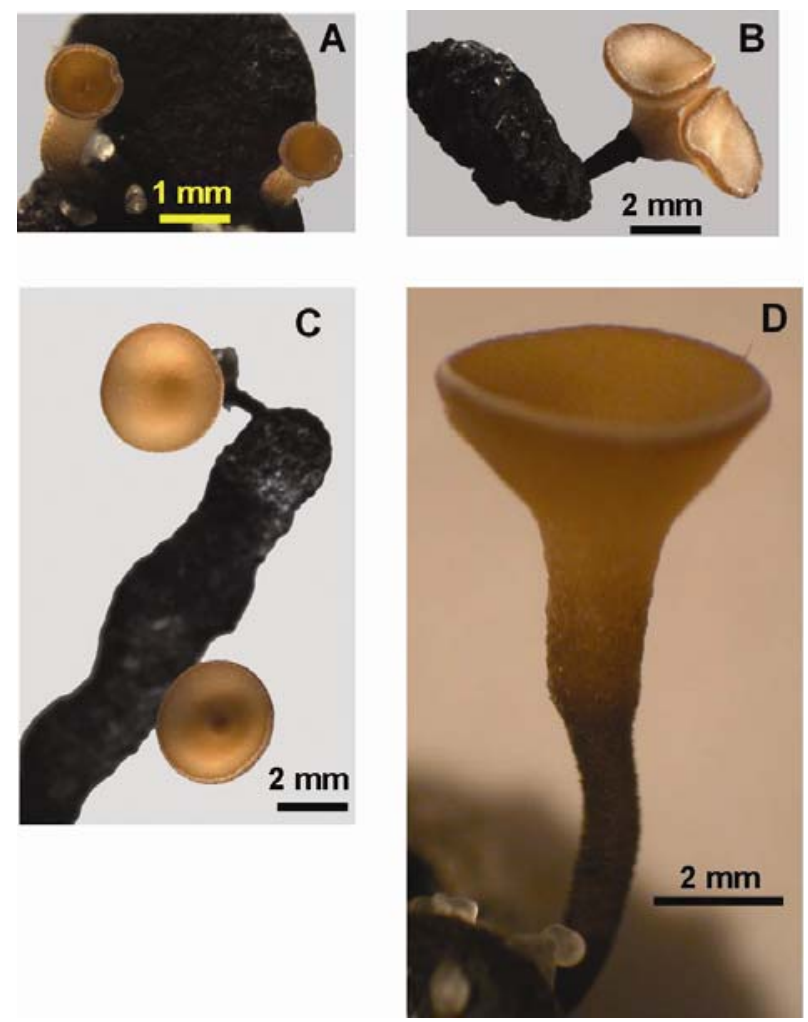

Fig. 2. Development of apothecia in Sclerotinia sclerotiorum. A, Immature apothecia. B, C, and D, Maturing apothecia with saucer shape and cup or funnel shape.

Table 1. Characteristics of selected Valencia peanut genotypes tested for resistance to Sclerotinia sclerotiorum isolate SS05-SC

\begin{tabular}{|c|c|c|c|c|c|c|c|}
\hline Genotype & Released by & $\begin{array}{c}\text { Growth } \\
\text { habit }\end{array}$ & $\begin{array}{c}\text { Plant } \\
\text { size }^{\mathrm{a}}\end{array}$ & $\begin{array}{c}\text { Maturity } \\
\text { (days) }\end{array}$ & $\underset{(\mathrm{kg} / \mathrm{ha})^{\mathrm{b}}}{\text { Yield }}$ & $\begin{array}{c}100 \text { seed } \\
\text { weight }(\mathrm{g})^{\mathrm{c}}\end{array}$ & Reaction $^{\mathrm{d}}$ \\
\hline Valencia-C & New Mexico State University (NMSU) & Bunch & Medium & 130 & 5118 & 50.6 & $\mathrm{~S}$ \\
\hline Georgia Valencia & University of Georgia & Bunch & Medium & 130 & 4074 & 57.8 & $\mathrm{~S}$ \\
\hline NM02565 & NMSU experimental line & Bunch & Medium & 125 & 6233 & 61.3 & $\mathrm{~S}$ \\
\hline
\end{tabular}

a Plant size at harvest. Varieties that describe plant size according to United States Peanut Descriptors, 1995. ARS Bull. 132. Small = "Chico," medium = "Early bunch," large = "Florigiant," and extra large = "BPZ53."

b Average of 2 years tested at 5 locations each year (location 1 - Clovis, NM; location 2 - Portales, NM; location 3 - Brownfield, TX; location 4 - Littlefield, TX; location 5 - Sudan, TX).

${ }^{c}$ Average of 1 year tested at 5 locations (location 1 - Clovis, NM; location 2 - Portales, NM; location 3 - Brownfield, TX; location 4 - Littlefield, TX; location 5 - Sudan, TX).

${ }^{\mathrm{d}}$ Reaction under laboratory conditions following inoculation at cotyledonary axils of 30 plants (15 plants in each of two trials) of each genotype with the darkly pigmented isolate of Sclerotinia sclerotiorum (see text). All genotypes were susceptible (S). 
Effect of medium on colony pigmentation. Mycelial growth and pigmentation was compared on PDA, potato agar (PA), and on sucrose-based and glucose-based media containing all or lacking one of the following ingredients: magnesium, potassium, phosphorus, and sulfur (12). Potato agar medium was prepared from $250 \mathrm{~g}$ of unpeeled, fresh, white potato, cut into small pieces, added to $500 \mathrm{ml}$ of distilled water in a 1-liter flask, and autoclaved for $15 \mathrm{~min}$ at $121^{\circ} \mathrm{C}$. The contents of the flask were passed through a metal screen overlaid with two layers of cheesecloth to separate the broth from potato pieces. Twenty grams of technical grade agar was added to $140 \mathrm{ml}$ of potato broth and $860 \mathrm{ml}$ of distilled water. This medium was autoclaved as described above and dispensed into 9$\mathrm{cm}$-diameter plastic petri plates. Mycelium plugs, $1 \mathrm{~cm}$ diameter, were cut from a 14day culture of $S$. sclerotiorum maintained on PDA medium at $5^{\circ} \mathrm{C}$ in the dark, and placed on the various media and incubated at $25^{\circ} \mathrm{C}$ in the dark. This experiment was repeated.

Pathogenicity. Seeds of cv. Valencia-C were surface-disinfested in $0.025 \%$ sodium hypochlorite and planted into plastic pots (with a volume of $340 \mathrm{~cm}^{3}$ ) filled with sterilized Terra-Lite Metro Mix 360 (W. R. Grace \& Co., Memphis, TN). In each of two trials, 25 plants at the third to fifth fully expanded leaf stage were inoculated by placing a 5-mm-diameter plug from a 5-day-old $S$. sclerotiorum PDA culture at one cotyledonary axil of each plant. For the five control plants, plugs from PDA were used. All plugs were covered with a
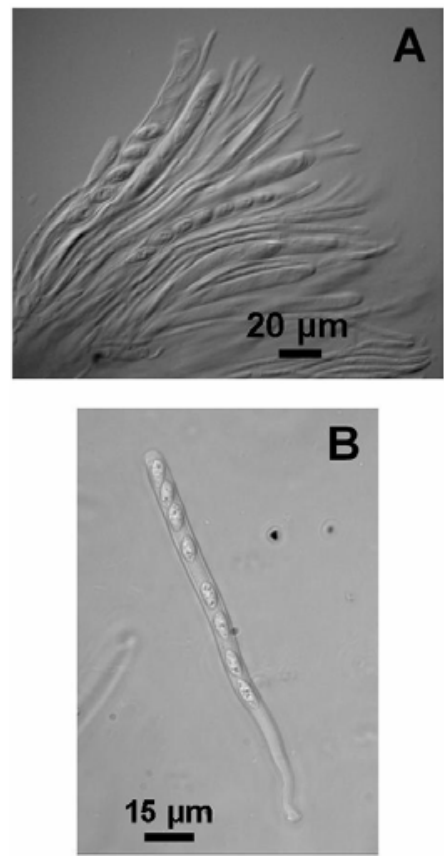

Fig. 3. Characteristics of asci and ascospores of Sclerotinia sclerotiorum. A, Asci and ascospores within hymenium of an apothecium. B, A single ascus with 8 ellipsoidal ascospores of uniform size. small piece of cheesecloth and all plants were placed in a moisture chamber at 23 to $25^{\circ} \mathrm{C}$. The moisture chamber was an aquarium box with a cover that housed a 15 -watt light unit providing $30 \mu \mathrm{mol} / \mathrm{m}^{2} / \mathrm{s}$, and had several perforations for air exchange. To increase relative humidity, water was added to the bottom of the aquarium box to a height of $5 \mathrm{~cm}$. Pots were placed on a plastic support above the water level. Plants were sprayed to runoff with sterile distilled water once a day and maintained in the aquarium box for 10 days.

Screening Valencia genotypes. Three high-yielding Valencia peanut genotypes, NM02565, Georgia Valencia, and Valencia-C (22), were challenged with isolate SS05-SC (Table 1). Methods for plant production and plant inoculation were the same as in pathogenicity test. Twenty plants of each genotype were evaluated in each of two trials, with 15 plants inoculated and five plants serving as controls.

\section{RESULTS}

Fungal isolation. All mycelial colonies from sclerotia, mycelium fragments, and stem tissues yielded indistinguishable darkly pigmented cultures on PDA, and sclerotia were produced on all cultures after 14 days. Sclerotia were large (>2 $\mathrm{mm}$ ) with variable shape.

Production of apothecia. Apothecia formation occurred in 6 weeks, and apothecia were beige to tan in color (Fig. 2). Immature apothecia (Fig. 2A) were 1 to 2 $\mathrm{mm}$ in diameter, while fully mature apothecia (Fig. 2B and C) were 4 to $6 \mathrm{~mm}$ in diameter with a stipe length of 3 to $5 \mathrm{~mm}$.
Initially, apothecia were flared with a thick rim (Fig. 2A), and then progressively differentiated into a saucer shape (Fig. 2B and $C$ ) with a thin rim and a cup or funnel shape (Fig. 2D).

Characteristics of apothecia, asci, and ascospores. Paraphyses were present in the hymenium (Fig. 3A), and asci were uniseriate with 8 ascospores per ascus, a tapered base (Fig. 3B), and an average length of $116.2 \mu \mathrm{m}$, based on 50 asci. Ascospores were 1-celled, hyaline, smooth, ellipsoidal, and uniform in size within asci with an average length of $13.06 \mu \mathrm{m}$ and width of $6.6 \mu \mathrm{m}$, based on 50 ascospores. These characteristics are consistent with those described for Sclerotinia sclerotiorum (13).

Effect of temperature on growth. Mycelial growth was sparse at 5 to $15^{\circ} \mathrm{C}$, optimal at $20^{\circ} \mathrm{C}$, reduced at 25 and $30^{\circ} \mathrm{C}$, and with no growth at $35^{\circ} \mathrm{C}$ (Fig. 4). Mycelium was initially white, but progressively became gray to dark brown. Pigmentation was more pronounced at temperatures above $20^{\circ} \mathrm{C}$.

Effect of medium on colony pigmentation. Pigmentation, gray to dark brown in color, was evident on PDA and PA media after 8 days of incubation, but was more pronounced on PDA than on PA (Fig. 5A). On PA medium, white fluffy mycelium and sclerotia were observed (Fig. 5A). No pigmentation was observed on glucoseand sucrose-based media (Fig. 5B); white fluffy mycelium and sclerotia were observed on all media except for sucrosebased media lacking phosphorus. Although mycelium grew within the agar of sucrose-

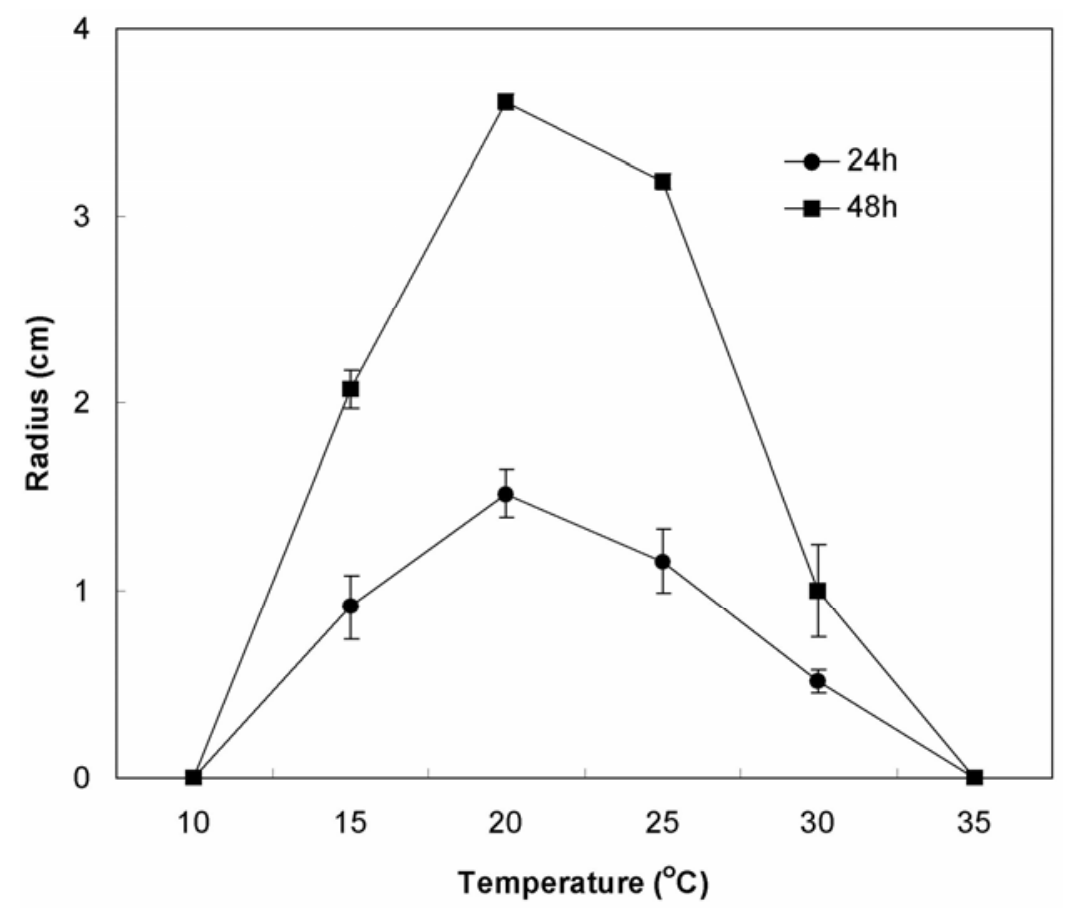

Fig. 4. Mycelial growth of Sclerotinia sclerotiorum on potato dextrose agar at various temperatures at 24 and $48 \mathrm{~h}$. All data points are the average of two experiments, and bars on data points are standard deviations. 

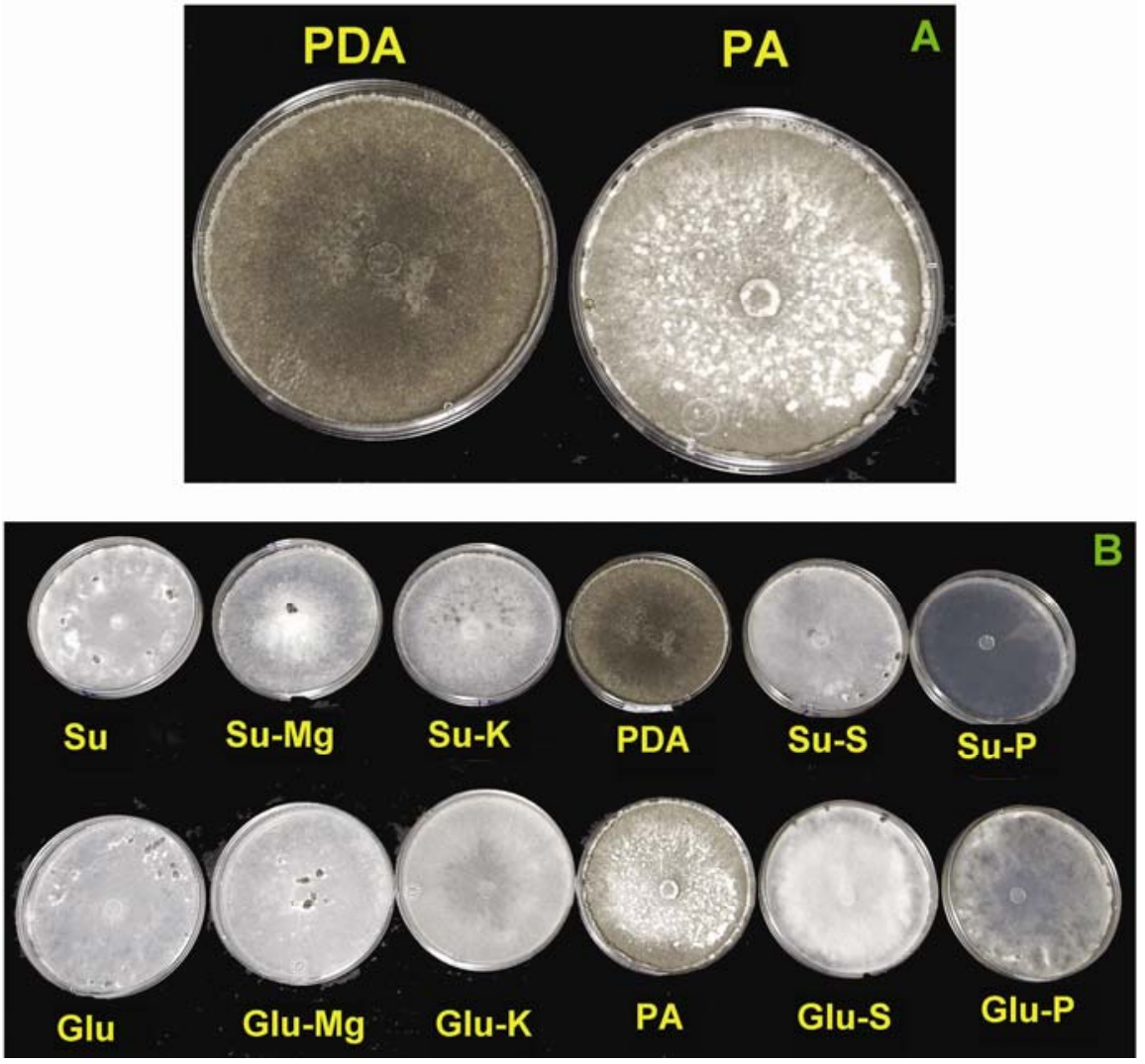

Fig. 5. Effect of growth media on colony pigmentation of Sclerotinia sclerotiorum. A, Mycelial growth on potato dextrose agar (PDA) and potato agar (PA). B, Mycelial growth on PDA and PA compared to growth on glucose- and sucrose-based media. The abbreviations Su, Su-Mg, Su-K, Su-S, and Su-P denote sucrose-based media with a complete set of nutrients, or lacking $\mathrm{Mg}, \mathrm{K}, \mathrm{S}$, or P, respectively. Similarly, the abbreviations Glu, Glu-Mg, Glu-K, Glu-S, and Glu-P denote glucose-based media with a complete set of nutrients, or lacking $\mathrm{Mg}, \mathrm{K}, \mathrm{S}$, or $\mathrm{P}$, respectively.

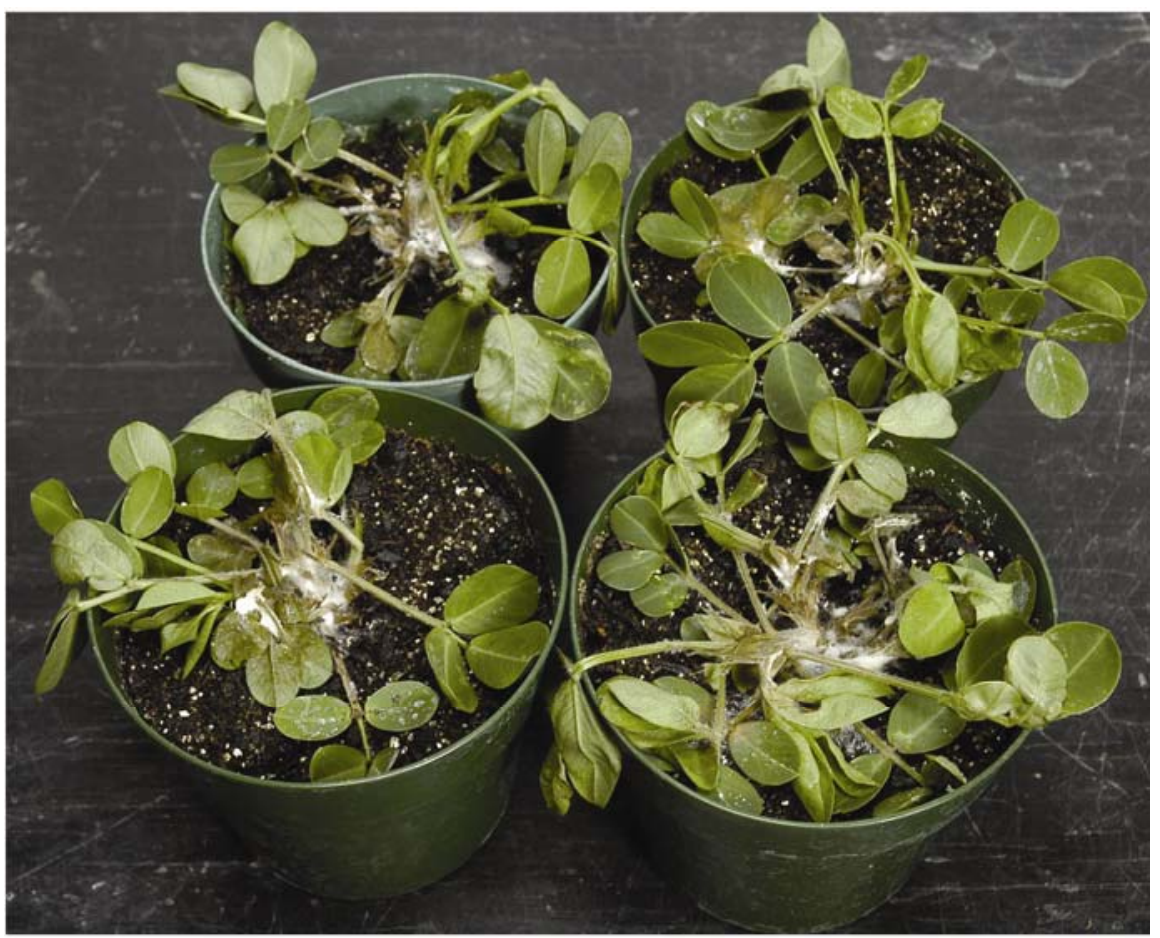

Fig. 6. Pathogenicity of Sclerotinia sclerotiorum on Valencia peanut (cv. Valencia-C, 7- to 10-leaf stage). Infected plants developed light tan to brown lesions on leaves and leaflets along with white fluffy mycelium with sclerotia. based media lacking phosphorus, there was no fluffy aerial vegetative growth, hence the clear appearance of these media (Fig. 5B).

Pathogenicity. After $48 \mathrm{~h}$ following inoculation, water-soaked and light tan lesions were visible on stems at points of inoculation. Between 3 and 7 days after inoculation, lesions progressed up the stems and petioles, eventually collapsing entire leaves. White fluffy mycelium was present on collapsed tissues. At 7 to 10 days following inoculation, sclerotia were visible on infected plants. Mycelium and sclerotia were collected and plated on APDA. Emerging colonies were transferred to PDA at 23 to $25^{\circ} \mathrm{C}$, and colonies were morphologically identical to those recovered from field-infected plants. Symptoms were not observed on the noninoculated control plants. In additional experiments, older peanut plants at the 7 to 10-leaf stage were inoculated with isolate SS05-SC of S. sclerotiorum as described above. Within 10 to 14 days, leaves covered with white fluffy mycelium collapsed (Fig. 6).

Screening Valencia genotypes. In the laboratory tests, water-soaked and light tan lesions formed at points of inoculation after $48 \mathrm{~h}$. Within 3 to 7 days of inoculation, lesions expanded into leaves. Plants from all three genotypes collapsed within 10 days of inoculation, and black sclerotia were formed. The three genotypes were equally susceptible to $S$. sclerotiorum (Table 1).

\section{DISCUSSION}

This is the first report of $S$. sclerotiorum on peanut in New Mexico. Infection of peanut by $S$. sclerotiorum has been reported in other states $(18,20,26,27)$. The unique characteristic of the isolates recovered in this study is the presence of darkly pigmented mycelium when grown on culture media. Several reports found the presence of white mycelium and dark sclerotia as identifiers of $S$. sclerotiorum $(5,8$, $18,26)$. However, this study indicates that such methods may be insufficient for accurate pathogen identification. This study clearly indicates that features such as types of apothecia, asci, and ascospores need to be examined in addition to colony morphology.

Only a few reports of $S$. sclerotiorum isolates with darkly pigmented mycelium have been published. These isolates are known to produce melanin (15). Results from this study concur with those reported by Lazarovits et al. (15), who showed that pigmentation in mycelium of $S$. sclerotiorum was influenced by the growth medium, and was more pronounced on potato dextrose agar obtained from commercial sources than on potato agar, a medium made from fresh potato broth and agar.

Several diseases caused by $S$. sclerotiorum on many crops are initiated by ascospores $(1,4)$. In this study, it is not 
known how infections of peanut plants by S. sclerotiorum were initiated. No ascocarps were observed at the time of the survey. When the blighted peanut plants were found, the only signs visible on the infected plants were whitish mycelium and sclerotia. It could not be determined whether infection was initiated by ascospores or sclerotia.

It is not known whether Sclerotinia blight, as reported in this study, resulted from contaminated seeds or from inoculum already present in the field soil. Although $S$. sclerotiorum may be present in the soil, it may not express activity if environmental conditions are not favorable. Such a scenario was reported from Georgia where, in spite of recovering $S$. sclerotiorum from soils, Sclerotinia blight was never found (27). However, in the growing season of 2004, Sclerotinia blight of peanut was found for the first time (26). Woodward et al. (27) attributed the manifestation of Sclerotinia blight to cool temperatures and prolonged moisture that prevailed during the late season.

Development of Sclerotinia diseases on various crops has been associated with high moisture conditions (high relative humidity, and excessive rainfall and irrigation) and cool temperatures $(1,7,19,21)$. The optimum temperature range for colonization of peanut plants and myceliogenic germination of sclerotia by $S$. minor was 20 to $25^{\circ} \mathrm{C}$, and more than $12 \mathrm{~h}$ of relative humidity between 95 to $100 \%$ was required for sclerotial germination (7). Phipps (19) investigated the environmental conditions preceding outbreaks of Sclerotinia on peanut and concluded that rainfall along with plant growth are the primary determinants for the initiation of Sclerotinia blight. Additionally, Phipps (19) observed that mean maximum and mean minimum air temperatures were approximately 32 and $20^{\circ} \mathrm{C}$, respectively, over a 15-day period prior to disease onset. It is not known when disease onset occurred in 2005 in New Mexico. However, environmental conditions, recorded in 2004 and 2005 from a weather station located approximately $12 \mathrm{~km}$ from peanut fields, were favorable for disease development. During the period from May (when peanut is planted) to October (when peanut is harvested), the average temperature and relative humidity levels observed in 2004 and 2005 were comparable to those recorded for the 9-year period from 1997 to 2005 (Fig. 7A and B). However, the average precipitation levels in 2004 and 2005, especially in the month of August, were greater than the level observed for the 9year period (Fig. 7C). It is plausible that cooler temperatures in combination with high precipitation in 2004 and 2005 may have contributed to the expression of Sclerotinia blight.

Several inoculation methods have been used in evaluating pathogenicity of Scle- rotinia species on peanut and in evaluating resistance of peanut to Sclerotinia blight $(10,17,18,26,27)$. In some studies, inoculations were performed by placing mycelium plugs or sclerotia on wounded (17) or unwounded detached leaflets (27), detached shoots (18), and wounded stems of standing plants $(26,27)$. In other studies, soil infestation was done by mixing a macerate of mycelium with the top layer of soil in which peanut was growing (20). In this study, plants were inoculated by placing mycelium plugs in cotyledonary axils. The advantage of this method is that it does not affect the physiological integrity of the plant as may be expected with detached
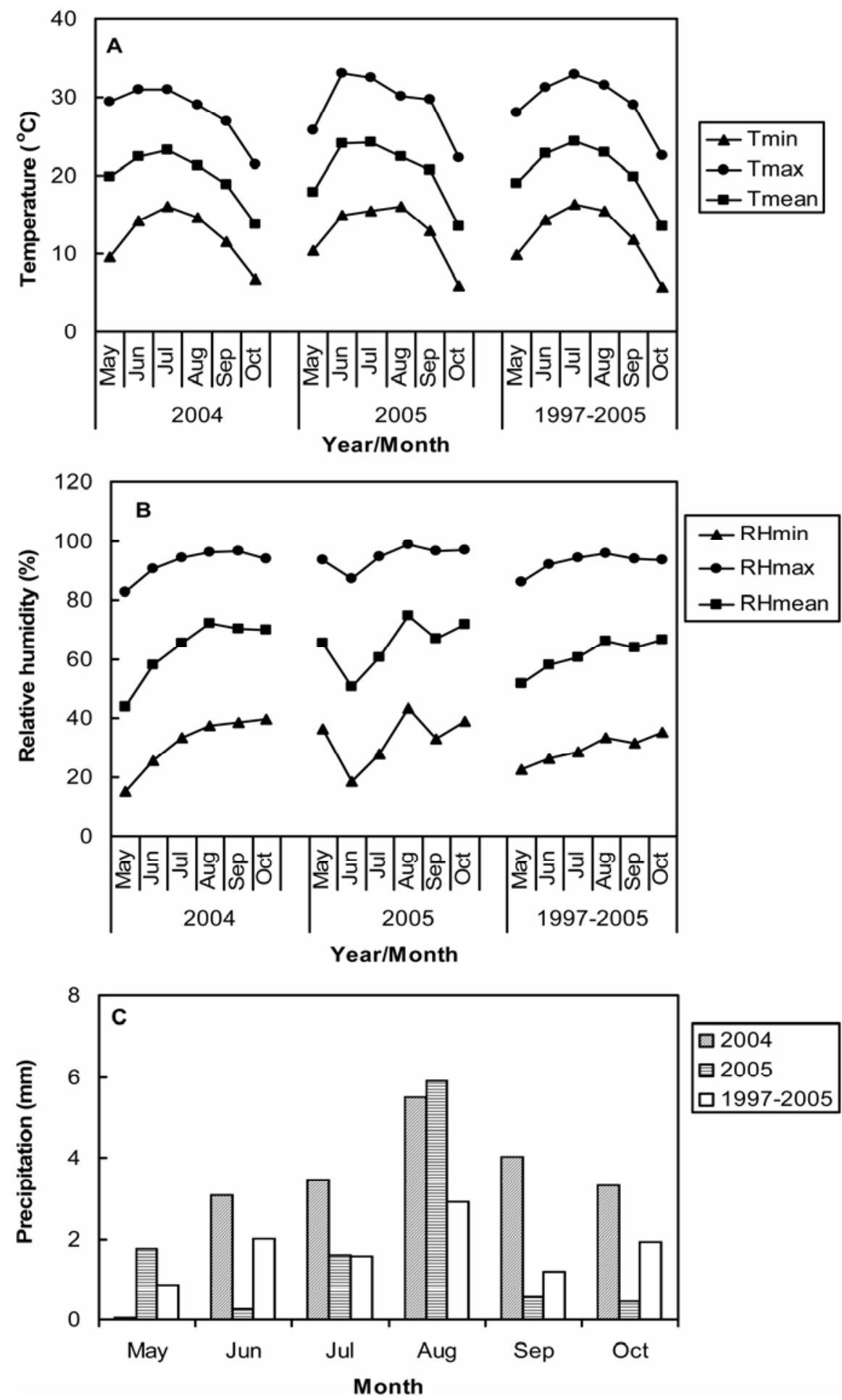

Fig. 7. Environmental data from May to October in 2004, 2005, and from 1997 to 2005 displaying A, mean monthly minimum (Tmin), mean monthly maximum (Tmax), and mean monthly air (Tmean) temperatures; B, mean monthly minimum (RHmin), mean monthly maximum (RHmax), and mean monthly (RHmean) relative humidity; and $\mathbf{C}$, mean monthly precipitation. Environmental data were obtained from a weather station located approximately $12 \mathrm{~km}$ from the field with Sclerotinia blight in eastern New Mexico. 
and wounded plant parts. Additionally, inoculation of cotyledonary axils circumvents the difficulty encountered in achieving uniform soil infestation when peanut plants are growing in the soil.

The potential of $S$. sclerotiorum to become a pathogen of peanut was demonstrated by Brenneman et al. (6) in 1991. However, the first evidence of plant infection in the field was not reported until 15 years later when environmental conditions became conducive to disease outbreak $(26,27)$. Therefore, it may be postulated that the ability of $S$. sclerotiorum to become a devastating pathogen of peanut is low insofar as environmental conditions are unfavorable to disease development. It is advisable to prevent the spread of this pathogen from the infested field to other fields by minimizing contamination of equipment used in several fields. Further monitoring studies should be conducted to determine the distribution of $S$. sclerotiorum and its impact on Valencia peanut in New Mexico.

\section{ACKNOWLEDGMENTS}

This work was financially supported by New Mexico State Agricultural Experiment Station. The authors thank C. Sanogo and S. L. Dwivedi for reviewing this manuscript. The authors also thank J. Drake and V. Espinoza for assistance with photography.

\section{LITERATURE CITED}

1. Abawi, G. S., and Grogan, R. G. 1979. Epidemiology of diseases caused by Sclerotinia species. Phytopathology 69:899-904.

2. Anonymous. 2006. Crop values, 2005 Summary. U.S. Dep. Agric., Natl. Agric. Stat. Serv., $\operatorname{Pr} 2(06)$.

3. Beute, M. K., Porter, D. M., and Hadley, B. A. 1975. Sclerotinia blight of peanut in North Carolina and Virginia and its chemical control. Plant Dis. Rep. 59:697-701.

4. Bolton, M. D., Thomma, B. P. H. J., and Nelson, B. D. 2006. Sclerotinia sclerotiorum (Lib) de Bary: Biology and molecular traits of a cosmopolitan pathogen. Mol. Plant Pathol. $7: 1-16$

5. Bradley, C. A., and del Rio, L. E. 2003. First report of Sclerotinia sclerotiorum on Niger (Guizotia abyssinica). Plant Dis. 87:602.

6. Brenneman, T. B., Sumner, D. R., and Phillips, D. V. 1991. Sclerotinia sclerotiorum on canola in Georgia and its potential as a pathogen on peanut. Plant Dis. 75:319.

7. Dow, R. L., Porter, D. W., and Powell, N. L. 1988. Effect of environmental factors on Sclerotinia minor and Sclerotinia blight of peanut. Phytopathology 78:672-676.

8. Garibaldi, A., Minuto, A., and Gullino, M. L. 2004. First report of white mold caused by Sclerotinia sclerotiorum on Hutchinsia alpina in Italy. Plant Dis. 88:1045.

9. Hollowell, J. E., Shew, B. B., Cubeta, M. A., and Wilcut, J. W. 2003. Weed species as hosts of Sclerotinia minor in peanut fields. Plant Dis. 87:197-199.

10. Hollowell, J. E., Shew, B. B., and Isleib, T. G. 2003. Evaluating isolate aggressiveness and host resistance from peanut leaflet inoculations with Sclerotinia minor. Plant Dis. 87:402-406.

11. Huang, H. C., Erickson, R. S., Van Hezewijk, B., and De Clerck-Floate, R. 2005. White mold of Houndstongue (Cynoglossum officinale) caused by Sclerotinia sclerotiorum in Canada. Plant Dis. 89:1013.

12. Jackson, A. M., Whipps, J. M., and Lynch, J. M. 1991. Nutritional studies of four fungi with disease biocontrol potential. Enzyme Microb. Technol. 13:456-461.

13. Kohn, L. M. 1979. Delimitation of the economically important plant pathogenic Sclerotinia species. Phytopathology 69:881-886.

14. Kokalis-Burelle, N., Porter, D. M., RodriguezKabana, R., Smith, D. H., and Subrahmanyam, P., eds. 1997. Compendium of Peanut Diseases, 2nd ed. American Phytopathological Society, St. Paul, MN.

15. Lazarovits, G., Starratt, A. N., and Huang, H. C. 2000. The effect of tricyclazole and culture medium on production of the melanin precursor 1,8-dihydroxynaphthalene by Sclerotinia sclerotiorum Isolate SS7. Pestic. Biochem. Physiol. 67:54-62.

16. Liddell, C. M., Christensen, N. B., Christensen, J. A., McEntee, J. P., and Waddell, C. A. 1991. Survey of peanut fields in Roosevelt County, New Mexico for Sclerotium rolfsii and Sclerotinia minor. Spring 1991. Agricultural
Experiment Station, Research Report no. 668 New Mexico State University.

17. Malcolm, D. L., Hampton, J. L., Phipps, P. M., and Grabau, E. A. 2005. Enhancing resistance to Sclerotinia minor in peanut by expressing a barley oxalate oxidase gene. Plant Physiol. 137:1354-1362.

18. Melouk, H., Jackson, K., and Damicone, J. 2003. First report of Sclerotinia blight on peanut in Nebraska. (Abstr.) Proc. Am. Peanut Res. Educ. Soc. 35:77.

19. Phipps, P. M. 1995. An assessment of environmental conditions preceding outbreaks of Sclerotinia blight of peanut in Virginia. Peanut Sci. 22:90-93.

20. Porter, D. M., and Beute, M. K. 1974. Sclerotinia blight of peanuts. Phytopathology 64:263-264.

21. Porter, D. M., and Melouk, H. A. 1997. Sclerotinia blight. Pages 34-36 in: Compendium of Peanut Diseases, 2nd ed. N. Kokalis-Burelle, D. M. Porter, R. Rodriguez-Kabana, D. H Smith, and P. Subrahmanyam, eds. American Phytopathological Society, St. Paul, MN

22. Puppala, N., Scott, A., Kirksey, R., Sanogo, S. and McAllister, F. 2006. Valencia peanut breeding line and multilocation variety testing. Pages 5-14 in: Peanut Research Results-2005. Annual Report, New Mexico Agricultural Experiment Station, Clovis, NM.

23. Tu, J. C. 1982. Membranous film on the developing apothecium of Sclerotinia sclerotiorum and its relationship to ascospore discharge. Can. J. Bot. 60:173-178.

24. Wadsworth, D. F. 1979. Sclerotinia blight of peanuts in Oklahoma and occurrence of the sexual stage of the pathogen. Peanut Sci. 6:7779.

25. Woodard, K. E., and Simpson, C. E. 1993. Characterization of growth and sclerotial production of Sclerotinia minor from peanut in Texas. Plant Dis. 77:576-579.

26. Woodward, J. E., Brenneman, T. B., Kemerait, R. C., Jr., Culbreath, A. K., and Clark, J. R 2006. First report of Sclerotinia blight caused by Sclerotinia sclerotiorum on peanut in Georgia. Plant Dis. 90:111.

27. Woodward, J. E., Brenneman, T. B., Kemerait, R. C., Jr., Culbreath, A. K., and Clark, J. R. 2006. Sclerotinia blight in Georgia and evidence for resistance to Sclerotinia sclerotiorum in runner peanuts. Plant Health Progress doi:10.1094/PHP-2006-0531-01-RS 